Workers personal questions. We conducted face to face interviews with some of the Sex Worker friendly GPs (General Practitioners) who provide sexual health certificates to Sex Workers. We have conducted telephone interviews with Sex Workers who do FIFO (fly in fly out) to regional mining towns in QLD. We collated this data with data provided by Respect Inc.

Results After collection of data we formatted charts and graphs. We found levels of STI's and HIV among Sex Workers were relatively low. GPs confirmed, Sex Workers are informed about STI's and HIV. Respect Inc provided data with hundreds of Sex Workers accessing offices across Qld for Safe Sex, STI's and HIV information, with positive sexual health outcomes.

Conclusion Sex Workers in Australia (QLD) have relatively low levels of STI's and HIV. Sex Workers are not the cause of increasing transmissions of STI's and HIV. Sex Workers often face stigma and discrimination in the wider community. Please respect Sex Work as a career of choice.

SEX WORK IS REAL WORK

\section{P14.21 THE IMPACT OF THE IEC (INFORMATION, EDUCATION AND COMMUNICATION) IN THE AFFIDAVIT OF SEX WORKERS}

Floribert Monga Lisangi*. Study Realized by the Youth Center Coulibaly Sidiki of the University of Kinshasa (Democratic Republic of Congo)

\subsection{6/sextrans-2015-052270.533}

Background Sex workers (sw) constitute a very important group in the transmission of HIV infection. Their sanitary and social follow-up has an impact in the prevention of HIV infection. Among strategies implemented at the youth centre Coulibaly sidiki of university of Kinshasa, the IEC occupies a very important place. We have realised a study in order to determine the impact of the IEC in the affidavit and prevention of STI and HIV next to sex workers.

Methods It's about prospective, descriptive study realised at the youth centre Coulibaly sidiki of the University of Kinshasa on a period of 3 months (September to November 2012).

We have included Sex Workers enrolled to socio-sanitary file of the centre, who came to make their medical visit during the period of study and who accepted to participate to the study.

They have been questioned through mid-directive questions sheet, oriented for the following data: socio-demographic data, questions concerning the sanitary follow-up, on going of IEC sessions, the impact of IEC sessions, in end some open question was devoted to possibility suggestions of SW to increase their follow-up.

Result Fifty two Sex workers were included. The mean age was 35 years. Among all of them 99\% was Christians. The majority of SW was living at Kinshasa (75\%). 62\% were divorced; $24 \%$ single; 6, 5\% widows. Among SW: 16 or $40 \%$ had minor children. More than the half of SW did not have an other professional activity and their intellectual level was low. During the IEC sessions $87 \%$ of SW were choosing themselves the themes to discuss: STI and HIV/AIDS (26\%), police harassment (12, 5\%); the solidarity between SW (16\%). The frequency of STI was $65,7 \%$ before the IEC sessions and $68 \%$ of SW ignored the type of STI. Systematic using of condom was 78,5\%. Concerning evaluation of their knowledge in the field of fighting against HIV and STI, acquired through IEC session: 30\% knew the HIV transmission's way, $14,5 \%$ recognised easily a STI.
Suggestions reached out by Sex Workers was to sustain session of IEC $37,5 \%$; diversify themes $15 \%$; changing schedule of IEC $12,5 \%$. A reconversion in others professional's activities and a funding of activity that generates profit (AGP) was the mains preoccupations of Sex Workers.

Conclusion Sex workers occupied an important place in the HIV and STI propagation because they constitute a gangway with the general population. The IEC is still to increase to acquire the best strategies of HIV and STI infection's prevention.

\section{P14.22 TO PREVENT HIVIAIDS THROUGH AWARENESS RAISING AND SOCIAL BEHAVIOURS CHANGE OF SEX WORKER IN BANGLADESH - AN EXPERIENCE FROM KANDAPARA BROTHEL, TANGAIL, BANGLADESH}

Tapas Kumar Saha*, Nari Mukti Sangha. Sabalia (Panjapara), Tangail-1900, Bangladesh

10.1136/sextrans-2015-052270.534

Issues Nari mukti Sangha (NMS) is a Self Help Group (SHG). We can awareness build up of SWs by (i) One-to-One Session (ii) Group discussion (iii) Peer education training (iv) HIV Test by ICDDRB Bangladesh (v) STI Clinic and (vi) Support services. Description NMS is a social service organisation, Government Registration no. TA-1333/2000. It is purely non-political and solely sex workers' organisation. Its aim is to establish the social, legal and human rights in the society and also women empowerment. We are directly involved to reduce STD/HIV/AIDS through awareness development and other intensive support services like STD clinic inside and outside of the brothel. Now we are working in trafficking field in Bangladesh. Before working in the field we do base line survey and post survey.

Lesson learned After completion the work the result one is SWs can encourage to use condom for protecting HIV/AIDS to the client. Another one is to establish the social and human rights in the society.

Conclusion SWs will develop capacity which will carry out the important benefit to prevent the HIV/AIDS program of our organisation. Nari Mukti Sangha is a fully committed to work with HIV/AIDS.

\section{P14.23 TRANSGENDER SEX WORKERS RESPONSE TO HIV IN PAPUA NEW GUINEA}

Obert Samba*. Save the Children in Papua New Guinea

\subsection{6/sextrans-2015-052270.535}

Introduction Save the Children SRH Poro Sapot Project is a national STI and HIV prevention project. The project represent the voice, health and interests of sex workers, MSM and Transgender people in Papua New Guinea at international and national levels so that they voice and health must be heard and their issues be considered.

Transgender women in Papua New Guinea, most of who were rejected by their own families are now on the streets doing sex work to survive. Sex work is illegal and most often they are faced with stigma and discrimination and violence. Over the years sex worker trannies have been infected and cannot access the health facilities because of our sexuality and therefore end up dying. The strong religious and cultural beliefs makes it hard for transgender sex workers to live a normal life. 